\title{
26 Methods AS THEORIES: Evidence and Arguments for Theorizing on Software Development
}

\author{
Steve Sawyer \\ Pennsylvania State University \\ University Park, PA U.S.A. \\ Hala Annabi \\ University of Washington \\ Seattle, WA U.S.A.
}

\begin{abstract}
In this paper we argue that software development methods represent theories on how best to engage the impressively complex and inherently sociotechnical activity of making software. To help illustrate our points we draw on examples of three software methods: the waterfall approach, packaged software development, and free/libre and open source software development, In doing this, we highlight that software development methods reflect- too often implicitly - theories of (1) how people should behave, (2) how groups of people should interact, (3) the tasks that people should do, (4) the order of these tasks, (5) the tools needed to achieve these tasks, (6) the proper outcomes of these tasks, (7) the means to make this all happen, and (8) that these relations among concepts are further set in specific social, cultural, economic, and industrial contexts. We conclude by highlighting three trends in conceptualizing these eight elements.
\end{abstract}

\section{INTRODUCTION}

Through this paper we argue that software development methods are vehicles for theorizing on the impressively complex and inherently socio-technical activity of making software. We support this argument by comparing the systems development lifecycle with packaged software development and free/libre and open source methods of software development. In revealing the implicit theorizing on software development, we depict aspects of the software development process affecting social inclusion.

Please use the following format when citing this chapter:

Sawyer, S., and Annabi, H., 2006, in IFIP International Federation for Information Processing, Volume 208, Social Inclusion: Societal and Organizational Implications for Information Systems, eds. Trauth, E., Howcroft, D., Butler, T., Fitzgerald, B., DeGross, J., (Boston: Springer), pp. 397-411. 
Framing software development as socio-technical is common (e.g., Sawyer 2004; Scacchi 2002b). A socio-technical lens demands we explicitly attend to the bound-up nature of people, particular technological elements, and the contexts of these nuanced interdependencies (Bijker 1995; Bijker et al. 1987; Law and Bijker 1992). ${ }^{1}$ Social aspects of software development include how people interact, behave, and organize. Technological aspects of software development include the use of methods, techniques, and computing technologies. In practice it is difficult to disentangle the ways people do things from the methods, techniques, and computing technologies they use for this doing.

We further note that software development differs from information systems development methods in at least two ways (Sawyer 2001). First, software development is focused on the development of an artifact--some defined set of working code that reflects specifications. An IS development effort is further focused on ensuring that software is brought together with specific users in specific organizational settings.

Second, current trends in labor specialization are reflected in differences among skill sets of those that develop software and those that implement IS. Simply, software engineers do different work than information systems consultants. These two groups of people also tend to work for different organizations, separate from one another and from the consumer organization (that purchased the software but needs an IS). This division of labor is made more clear by considering the business analysts, trainers, technical specialists, usability staff, and others who serve to make an IS from software.

The range of new approaches to both software and IS development, the constant evolution in current approaches, and the ongoing attention suggest that our theorizing is still incomplete. Here we focus specifically on the underlying, and too-often implicit, elements of this theorizing. We begin by arguing that all software development methods have eight common elements. To support this argument we draw on a comparison of three software development approaches. We conclude with specific suggestions for improving our theorizing on methods.

\section{SOFTWARE DEVELOPMENT AS THEORIZING}

We contend that software development methods are a form of theory. ${ }^{2}$ A theory is a relationship between (or among) two (or more) concepts (Merton 1967). The simplest form is causal: "A" leads to " $B$." An example would be to be born (A) leads to, at some point, dieing (B). Typically the goal of theory is to develop the relationships among the constructs to such a point that the theory is general, specific, and accurate. These three criteria, however, are not mutually attainable. The principle known as "Occam's razor" suggests that any theory can pursue two of three criteria, sacrificing the third. In our example, we pursued accuracy and generality, but could not pursue specificity.

\footnotetext{
'This conceptual perspective is increasingly known as social informatics. A simple summary of social informatics is presented in Sawyer (2005). More complete discussions can be found in Kling $(1999,2000)$ and Kling et al. (2005).

${ }^{2}$ In this paper we make the claim and illustrate our position, leaving to other papers the conceptual justification. The value of this paper is the support we can provide this premise.
} 
Developing, testing, and using theory are central goals of contemporary scholarship. Variations in representation, notation, value of directionality, and centrality of theory are contentious topics in every academic discipline. We acknowledge the passion this topic engenders, leaving to others a more detailed engagement. Our point in raising theory as a scholarly goal is to aver that in software development, methods are forms of theory (they identify concepts and presuppose relations). Weick (1995) makes clear that this is a process, one he calls theorizing. He goes on to argue the importance of making theorizing more visible to scholars and others. We agree and in this paper do so by examining the common conceptual elements that make up software development methods-as-theory. ${ }^{3}$

\subsection{Socio-Technical Theorizing}

Our efforts to theorize software development as a socio-technical activity builds on the social-shaping of technology (SST) perspectives developed in Bijker (1995), Law and Bijker (1992), and Bijker, et al. (1987). The SST perspective highlights that the material characteristics and actions of any technology are shaped by the social actions of the designers, the specific uses of that technology, and the evolving patterns of use over time. This differs from the codesign approach that is prevalent in North America. As Scacchi (2005) notes, the codesign approach too often evolves into a benign neglect of the interaction between what is social and technical, leading to an evocation of the concepts without a concomitant analytical activity.

Bijker's four socio-technical principles frame our theorizing. The seamless web principle states that any socio-technical analysis should not a priori privilege technological or material explanations ahead of social explanations, and vice versa. The principle of change and continuity argues that socio-technical analyses must account for both change and continuity, not just one or the other. The symmetry principle states that the successful working of a technology must be explained as a process, rather than assumed to be the outcome of "superior technology." The actor and structure principle states that socio-technical analyses should address both the actor-oriented side of social behavior, with its actor strategies and micro interactions, and the structure-oriented side of social behavior, with its larger collective and institutionalized social norms and processes.

\subsection{Software Development Methods as Socio-Technical Theories}

Two elements of any software development method-as-theory are guidance on how people should behave and how groups of people should interact. For example, one might theorize that people are to share information selflessly and pursue egoless

${ }^{3}$ In this paper we take the first step of engaging the concepts that are part of software development methods as theory, leaving to future work the task of sorting through the relationships among these concepts. 
programming. Another approach would be to theorize that people will have differences of opinion and that there will be interpersonal conflict among team members.

Software development methods also reflect a set of expectations relative to the tasks that people should do, the order of these tasks, and the tools needed to achieve these tasks. The details of conduct, input and output elements, sequencing, and resource needs of tasks are central elements of any software development method and the core of this discourse (e.g., Cubranic and Booth 1999; Egyedi 2004).

The proper outcomes of these tasks continue to be an active area of scholarship. One trend is a steady movement toward multiple measures and to focusing on measurement of use in addition to measures of the software artifact's structure, size, and technical performance (Melone 1990). The rise of open source development has elevated the attention to theorizing on the reasons why developers perform, and the incentives that encourage (and discourage) performance (e.g., Bergquist and Ljungberg 2001).

Software development methods also incorporate, explicitly or implicitly, relations to specific contexts. For example, clean-room, participatory, and packaged software development approaches demand separation, inclusion, or distance from various groups of users. The literature on virtual teams and distributed development make clear a second form of context (geography) (e.g., Moon and Sproull 2000). The differences among custom and packaged software further suggest that the industrial environment matters (e.g., Sawyer 2000).

In sum, as laid out in Table 1, software development methods are explicit representations of (1) how people should behave, (2) how groups of people should interact, (3) the tasks that people should do, (4) the order of these tasks, (5) the tools needed to achieve these tasks, (6) the proper outcomes of these tasks (including means and ways to evaluate these outcomes), and (7) the means to make this all happen. The relations among these concepts are further set in (8) specific contexts, implying that the exact nature of such relations are contingent to some degree on the larger social milieu.

Table 1. Concepts Important to Theorizing Software Development Methods

\begin{tabular}{|l|l|}
\hline \multicolumn{1}{|c|}{ Element } & \multicolumn{1}{c|}{ Details } \\
\hline $\begin{array}{l}\text { People's individual } \\
\text { behavior }\end{array}$ & What is expected of people engaged in developing software \\
\hline $\begin{array}{l}\text { People's collective } \\
\text { action }\end{array}$ & $\begin{array}{l}\text { The interactions among people working together to develop } \\
\text { software }\end{array}$ \\
\hline Task selection & $\begin{array}{l}\text { The particular tasks that need to be done to develop } \\
\text { software }\end{array}$ \\
\hline Task ordering & The ordering of the particular tasks to develop software \\
\hline Tool support & $\begin{array}{l}\text { The roles and featured of tools used to support } \\
\text { tasks/ordering }\end{array}$ \\
\hline $\begin{array}{l}\text { Outcomes } \\
\text { (measures) }\end{array}$ & $\begin{array}{l}\text { The elements measured to assess both progress and } \\
\text { completion }\end{array}$ \\
\hline Incentives & $\begin{array}{l}\text { The structures put in place to encourage positive, and } \\
\text { discourage negative, behaviors and interactions }\end{array}$ \\
\hline Contexts & $\begin{array}{l}\text { The larger social, cultural, economic and industrial milieu } \\
\text { in which software development takes place }\end{array}$ \\
\hline
\end{tabular}




\section{COMPARING SDLC, PACKAGE AND FREE/LIBRE OPEN SOURCE SOFTWARE APPROACHES}

To illustrate how these eight concepts underscore methods, we compare three approaches to developing software. We select the SDLC, packaged software development, and FLOSS methods, providing in this section a brief review of these three approaches before developing our comparison (this is summarized in Table 2).

\subsection{Systems Development Life Cycle}

The systems development life cycle (SDLC) or waterfall approach is well-known, oft-referenced, and rarely followed. In the SDLC, specific steps are linearly sequenced with some overlap between steps to allow for knowledge transfer. Specific skills and resources for each step, its inputs and outputs, and proper approaches to pursuing the transfer of inputs to outputs are documented.

The premise of the SDLC is that process drives outcomes. The measures for SDLC success typically include cost, quality, and user satisfaction as recognition of value to the larger corporate mission. Implicit in the SDLC are at least two relevant assumptions. First, it implies that software development takes place within one organization (or, at least, is totally controlled by that organization - i.e., when hiring a contractor or consultant to construct a custom product). This reflects vertical integration (a hierarchy). Second, the SDLC is focused on building, not buying, software. This is appropriate, for that was its purpose.

Staff costs should be minimized and typical SDLC-based efforts are characterized by team membership turnover, division of labor by both phase and function, and disbanding following the completion of the first release (Cusumano and Smith 1997). Thus, these are more like ad hoc work groups, not teams (Goodman et al. 1986).

\subsection{Packaged Software Development}

Packaged software--also known as shrink-wrapped, commercial-off-the-shelf (COTS), and commercial software-means the code is sold as a (licensed) product (purchased from a vendor, distributor or store) for all computer platforms including mainframes, work-stations, and microcomputers (Carmel 1997; Carmel and Sawyer 1998; Sawyer 2000).

In PSD, time pressures (not cost) drive development. Packaged software developers tend to have a product (not process) view of development (Carmel 1995; Carmel and Becker 1995; Cusumano and Smith 1997). A product focus means that the dominant goal of the software development effort is to ship a product This product focus also implies that these products have distinct trajectories with the software evolving through a planned set of releases. 
Table 2. Comparing SDLC, Package and FLOSS Development Approaches

\begin{tabular}{|c|c|c|c|}
\hline Element & SDLC & Package & Open Source \\
\hline $\begin{array}{l}\text { People's } \\
\text { individual } \\
\text { behavior }\end{array}$ & $\begin{array}{l}\text { Process-focused, } \\
\text { specialized to parti- } \\
\text { cular roles, sequenced, } \\
\text { ego-less, and sharing- } \\
\text { oriented }\end{array}$ & $\begin{array}{l}\text { Product-focused, } \\
\text { competitive, skill- } \\
\text { based, interdependent, } \\
\text { time-pressured }\end{array}$ & $\begin{array}{l}\text { Self interest, skill- } \\
\text { focused and altruistic. }\end{array}$ \\
\hline $\begin{array}{l}\text { People's } \\
\text { collective } \\
\text { action }\end{array}$ & $\begin{array}{l}\text { Collective, controlled } \\
\text { and focused on error } \\
\text { reduction }\end{array}$ & $\begin{array}{l}\text { Conflictual, focused on } \\
\text { delivery, and coding }\end{array}$ & $\begin{array}{l}\text { Product focused, } \\
\text { focused on personal } \\
\text { goals and producing a } \\
\text { public good }\end{array}$ \\
\hline Task selection & $\begin{array}{l}\text { Defined by system } \\
\text { requirements and } \\
\text { mostly inflexible }\end{array}$ & $\begin{array}{l}\text { Group defined and } \\
\text { mostly flexible }\end{array}$ & $\begin{array}{l}\text { Driven by self interest } \\
\text { and supported by a } \\
\text { merit system }\end{array}$ \\
\hline Task ordering & $\begin{array}{l}\text { Prescribed by phase or } \\
\text { function }\end{array}$ & Iterative & $\begin{array}{l}\text { Fluid, flexible, often } \\
\text { iterative }\end{array}$ \\
\hline Tool support & $\begin{array}{l}\text { Enforce control and } \\
\text { process adherence }\end{array}$ & $\begin{array}{l}\text { Support interactions } \\
\text { and interdependencies }\end{array}$ & $\begin{array}{l}\text { Support interaction and } \\
\text { sharing code }\end{array}$ \\
\hline $\begin{array}{l}\text { Outcomes } \\
\text { (measures) }\end{array}$ & $\begin{array}{l}\text { Adoption, customer } \\
\text { satisfaction, cost }\end{array}$ & $\begin{array}{l}\text { Market share, user and } \\
\text { industry reviews }\end{array}$ & $\begin{array}{l}\text { Developer satisfaction, } \\
\text { market share, reviews, } \\
\text { portability }\end{array}$ \\
\hline Incentives & $\begin{array}{l}\text { Income, skill- } \\
\text { development }\end{array}$ & Profit, recognition & $\begin{array}{l}\text { Developer personal } \\
\text { satisfaction, project } \\
\text { and developer recog- } \\
\text { nition, public good }\end{array}$ \\
\hline Contexts & Organizational & Market driven & User-base \\
\hline Notes & $\begin{array}{l}\text { Users involved through } \\
\text { intermediaries }\end{array}$ & $\begin{array}{l}\text { Users involved through } \\
\text { intermediaries }\end{array}$ & $\begin{array}{l}\text { Users directly involved } \\
\text { (developers are often } \\
\text { users, and users test } \\
\text { and fix bugs and } \\
\text { contribute code) }\end{array}$ \\
\hline
\end{tabular}

In packaged software firms, developers hold line positions so their needs are central to the performance of the organization. In effect, they are the company's production mechanism as they generate revenue. Packaged software developers often have at best a distant relationship with their user population. This separation means that intermediaries - such as help desk personnel and consultants - link users to developers (Grudin 1991; Keil and Carmel 1995; Maiden and Ncube 1998).

Packaged software products are measured by criteria such as favorable product reviews in trade publications, the degree of "mind share" - the awareness of a product in the minds of the target population, developing a large installed base and/or creating new markets (Andersson and Nilsson 1996; Brynjolfsson 1994). 


\subsection{Free/Libre Open Source Software}

FLOSS is a broad categorization used to describe software developed and released under various "open source" licenses. Licenses offer a range of features, all allowing inspection of the software's source code. We use the term FLOSS to encompass the free software movement, which also releases software along the same terms as the OSS movement, but with a distinction that derivative works must be made available under the same nonrestrictive license terms. FLOSS projects comprise of a varying number of developers ranging from a few to a hundred or more. FLOSS development groups are groups working in distributed computer-mediated networked form (Scacchi 2002b).

FLOSS members interact primarily or exclusively via computer-mediated communications (CMC). Project members coordinate their activities primarily through private e-mail, mailing lists, bulletin boards, and chat rooms and use compilers, bug tracking, and version control systems for their software development.

In general, FLOSS processes are fluid not, complying with any particular software engineering method (Raymond 1998; Scacchi 2002). One of the most commonly mentioned models used to explain the methods or practices of FLOSS development is Raymond's (1998) "The Cathedral and the Bazaar" metaphor. Raymond depicts FLOSS developers as autonomously deciding schedule and contribution modes for software development as merchants in a bazaar would, thereby dismissing the need for central coordination as the construction of a cathedral would in a master architect. The bazaar metaphor is limited as it diminishes aspects of the FLOSS development process, such as the role of the project leader or core group and the existence of de facto hierarchies (Bezroukov 1999).

In FLOSS, a mixture of self-serving and altruistic goals drive development. Developers join FLOSS projects for one or more of several reasons, some of which are employment (as some FLOSS developers are employed by formal organizations to develop software), to meet a personal need, to contribute to creating a public good, to gain satisfaction from the software development process, and/or for potential career gains (Moody 2001).

Members of any project move from peripheral roles to a core developer role in the project through a merit-based process (Cubranic and Booth 1999). An individual's technical expertise and participation in developing the product results in his/her inclusion in the core group of developers. However, to become one of the core developers means they must have a detailed understanding of the software and development processes. Since there is no separate documentation for system requirements or design, this poses a significant barrier to entry (Fielding 1997; Hecker 1999). Designs and requirements evolve over time and are implicitly articulated in public mailing lists as a result of individual developers' desired functionality and a developer's willingness to implement them (Scacchi 2002b). Tasks are accomplished based on developers' needs and interests and articulated in to-do lists as seen in Apache Web Server in the early years (Annabi 2005).

FLOSS software success is measured by a variety of criteria. User satisfaction, portability, favorable product reviews, learning opportunities, user-base, developer satisfaction and developer recognition are some of the measure of FLOSS success (Crowston et al. 2003). Portfolios of measures can be used to assess any particular project depending on project and members goals. 


\subsection{Methods as Theories: Comparing the Three Approaches}

In Table 2 and below we highlight via comparisons how the eight elements of a software development method reflect theorizing. A complete analysis is beyond the scope of this paper; so, here we summarize the concepts. We note the presence of these concepts in each of the three approaches, leaving to other work attention to relationships among the concepts.

People's individual behavior. Each of the three approaches make clear expectations for a certain set of behaviors from people. In the SDLC, people are to attend to process, share information, suppress ego issues, and focus on developing role-specific technical and professional skills. The PSD approach conceives of people as productfocused, competitive, technically skilled, with limited need for social skills, willing to take risks, and time-pressured. In FLOSS, people are seen as pursuing a mix of altruistic and self-serving goals, constrained by social controls, and with high technical skill levels.

People's collective action. In the SDLC, people are expected to be oriented to the goals of the collective and consensus is expected. In PSD, people's interactions will be guided by product needs, time pressures, and profit, and conflict is expected. In FLOSS, people's collective behavior is guided by the twin goals of public good and personal needs, and interactions are driven by performance goals.

Task selection. In the SDLC, tasks are predefined by the method and system requirements-an engineering ethic. The task inputs, outputs and means of proceeding are specified and often inflexible. In the PSD approach, tasks are more flexible, although there are common templates or forms that must be met. In FLOSS, tasks are mostly left to the developers, with a few (such as version control) serving as central aspects of the effort. These tasks help to structure FLOSS.

Task ordering. In the SDLC, task ordering is typically fixed, linear, and prescribed. In PSD, the ordering of tasks is more fluid while particular inputs and outputs are less prescribed. It is difficult to develop a task ordering in FLOSS beyond observing that certain tasks (such as the use of a configuration management tool) serve as central and structuring elements of the approach.

Tool support. In the SDLC, software tools are used to enforce task ordering and task completion (a controlled production environment). These tools are often integrated, complex, and have limited flexibility. In both the PSD and FLOSS approaches, tools are engaged that support collaboration, coordination, and production support. These tools are more flexible, less integrated, and often quite simple.

Outcomes (measures). In the SDLC, process measures are used, and these measures focus on cost, quality, and user take-up/value. In PSD, product measures are used, and these measures focus on installed base/market share, sales, margin, and defect rates. In FLOSS, there is a combination of product and personal measures. This remains an active area of inquiry and continues to be poorly understood (see Crowston et al. 2003).

Incentives. In the SDLC, developers' behaviors are motivated by salary/income, since developers are employed, as well as opportunities to learn new skills from developing particular software. In PSD, incentives extend past salary to include stock 
options and shares of sales. In FLOSS, there are a variety of incentives depending on circumstances, but generally, developers are interested in developing a product for the common good while meeting their own needs, attaining satisfaction from engaging in the development process, and potentially gaining recognition for themselves and the project.

Contexts. In the SDLC, software development occurs in the context of organizational goals, needs, and capabilities. The main purpose is to meet organizational objectives within limited budgets while accommodating social, technological, and political factors. In the SDLC, risk mitigation is a central issue. In PSD, software is developed to meet a need present or forecasted in the market, and to pursue opportunities. In PSD, taking on risk is a central issue. In FLOSS, software is developed by users for users as ideas about the product evolve over time with user influence being the main driver. In FLOSS, risk is borne primarily by individuals.

We further note that the roles that users play shape development. And, this shaping has both a direct and an indirect component. For example, in the SDLC, users are the focus of one phase, and then kept distant from the development effort. However, a focus on meeting user's needs dominates the SDLC approach. In PSD, users are always distant, but there are extensive efforts to gather user needs and monitor their interests. These efforts, however, are one of several factors that influence design. In FLOSS, developers are often users and the blurry boundary between users and developers creates an interesting dynamic for development.

Table 3. Observations on Theorizing Software Development Methods

\begin{tabular}{|l|l|}
\hline \multicolumn{1}{|c|}{ Element } & \multicolumn{1}{c|}{ Details } \\
beople's individual & $\begin{array}{l}\text { An increasingly richer view of people as having passion, } \\
\text { engaging conflict and pursuing personal agendas (not just as } \\
\text { error-producing and limited cognitive agents). }\end{array}$ \\
\hline People's collective action & $\begin{array}{l}\text { Interactions among people are central characteristics of } \\
\text { methods and must be accounted for in the design of tasks, } \\
\text { tools and outcome measures. }\end{array}$ \\
\hline Task selection & Tasks are becoming more fluid and more flexible. \\
\hline Task ordering & Task ordering is becoming less linear. \\
\hline Tool support & $\begin{array}{l}\text { Tool support moving towards supporting interaction and } \\
\text { access to materials, not (just) code production and process } \\
\text { enforcement. }\end{array}$ \\
\hline Outcomes (measures) & Measures are expanding and evolving. \\
\hline Incentives & $\begin{array}{l}\text { Incentives are under-explored (though FLOSS approaches } \\
\text { require engaging this directly). }\end{array}$ \\
\hline Contexts & $\begin{array}{l}\text { Contexts are under-explored (though evidence and } \\
\text { awareness that a one-size-fits-all approach to software } \\
\text { development is growing). }\end{array}$ \\
\hline Notes & $\begin{array}{l}\text { The number, needs, skills, social power and other resources } \\
\text { of users have substantial and multiple, indirect, effects on } \\
\text { how software is developed. }\end{array}$ \\
\hline
\end{tabular}




\subsection{Observations}

Drawing on this analysis, in Table 3 and below we summarize and discuss eight observations regarding software development methods as incipient theories.

People's individual behavior. We observe a trend toward a more complex view of people as having passion, engaging conflict, and pursuing personal agendas (not just as error-producing and limited cognitive agents). This is most evident in FLOSS development as one of the top reasons and features of the development process is "satisfying an itch" for developing and creating to meet needs (Crowston et al. 2003).

People's collective action. We note that there is a shift toward conceiving the interaction among people as central characteristics of methods that must be accounted for in the design of tasks, tools, and outcome measures. Both the PSD and FLOSS literature make clear that managing interactions are central issues to success (Annabi 2005; Crowston et al. 2003; Sawyer 2000).

Task selection. We observe that task structures are seen as more fluid and responsive. Tasks are defined and chosen through consensus and conflict and with user involvement. As in the cases of both PSD and FLOSS, developers define tasks through interactions categorized by both conflict and consensus.

Task ordering. We observe that task ordering is becoming more iterative, with expectations among developers and users that specific tasks are likely to have multiples passes. A second aspect of this iterative orientation is the increased flexibility in the order of tasks.

Tool support. We observe that the roles and uses of software development tools are moving toward supporting interaction and access to materials. In doing this, the tools are moving away from focusing solely on code production and process enforcement. The most vivid example of this is the FLOSS uses of version control software (Shaikh and Cornford 2004).

Measures. The number of measures being used to evaluate software development continues to expand. These measures can be seen as a suite and encompass developer behavior, development team processes, measures of use and value to customers, and measures of the artifacts size, quality, and resources.

Incentives. It appears that incentives (and disincentives) remain an under-explored area in SDLC and PSD. FLOSS development suggests that incentives are both intrinsic and extrinsic (Crowston et al. 2003), affecting developers' interactions with the product and others in the development group.

Contexts. We observe that the professional community of software developers, and many in the academic community studying software development, are aware that there is no one-size-fits-all approach to software development. There are, however, common elements that define software development (the point we are arguing here) and that the way these elements are engaged is driven in part by the context. This contingency perspective suggests that differences in software development methods are critical.

For more than 20 years, scholars have noted that the number, needs, skills, social power, and other resources of users have substantial and multiple effects on how software is developed (e.g., Keil and Carmel 1995; Kling and Iacona 1984; Markus 1983) and how it meets the needs of underserved groups. It appears this user pressure is influencing the recent work in software development methods. We further note that 
the variations among these concepts across the three examples suggests that while the concepts are common, the pattern of relationships among these concepts differs.

\section{IMPLICATIONS}

We have argued here that software development methods can be best understood as theories and posited that these engage eight concepts. Drawing on a comparison of three approaches, we have observed that social inclusion (e.g., users and uses) helps to shape software development in many direct and indirect ways. In Table 4 and below, we look beyond our current observations to speculate on how we might advance theorizing on software development methods.

\subsection{More Complex Representations of People's Behaviors}

We expect that future software development methods will have more nuanced and complex representations of people's behaviors. For example, we expect that developers will be increasingly construed as problem-solvers (and not error-prone code writers) (Mockus and Herbsleb 2002). In part this more complex view of software developers is driven by our increased understanding of their work. It may also, at least indirectly, draw on our increased understanding of knowledge-based work. That is, we see software developers as knowledge workers, and increasingly they are able to choose what projects to join (Annabi 2005; Drucker 1998). This more inclusive view of people's behaviors is likely to drive a resurgence of empirical studies on performance and process (such as is seen in the FLOSS literature).

A second trend we expect to see in future theorizing on software development is that the interactions among people, and among people and the various tools and repositors used in developing software, will be seen as a central activity (e.g., Mockus and Herbsleb 2002; Scacchi 2002a). As we note below, this will influence the design and uses of tools and incentives. This trend is likely to be instantiated in guidance for pair programming, team development, structured communication, shared work environments, and a more discourse-oriented approach to documenting decisions.

Table 4. Guidance for Continued Theorizing on Software Development Methods

\begin{tabular}{|ll|}
\hline \multicolumn{2}{|l|}{ Leverage Points: } \\
\hline 1. & More complex representations of people's behaviors \\
\hline 2. & More fluid task elements supported with more flexible tools \\
\hline 3. & Increased integration of incentives, measures and context \\
\hline
\end{tabular}




\subsection{More Fluid Task Elements Supported with More Flexible Tools}

We speculate that future theorizing on software development methods will build on the concepts of templates. A template-oriented view makes clear that these structures are a guide, to be interpreted, not followed. In contrast, the SDLC and other recipebased views makes guidance more like scripts: inflexible and increasingly unwieldy (as exceptions and errors lead to expanded scripting). The move toward templates means a blurring of tasks and ordering (even though the focus on particular inputs and outputs will sharpen). So, even as the sequence of tasks becomes more fluid, and perhaps less linear, the specific needs at templated points will increasingly become clearer (and better understood). And, as noted above and in Sawyer (2004), we speculate that the tools used will better support people's collaboration and interaction-going beyond production and control functions (e.g, Vessey and Sravanapudi 1995).

\subsection{Increased Integration of Incentives, Measures and Context}

Future theorizing on software development methods will better align participant's incentives with tasks and in doing this, these incentives will reflect the more creative, problem-solving, collaborative nature of people (Halloran and Scherlis 2002; Mockus and Herbsleb 2005; Scacchi 2005). These incentives are likely to draw on multiple measures and a better understanding of tradeoffs (e.g., for FLOSS portfolios of measures suggested by Crowston et al. 2003). And, these methods will reflect contingencies such as contextual pressures and needs, including users' engagement issues. This is especially significant to the issue of social inclusion. The inclusion of underrepresented groups in the software development process produces software that is consistent with their needs leading to their inclusion.

Looking beyond these specific speculations regarding future theorizing on software development methods, we argue that such work will explicitly or implicitly engage the relationships among eight core concepts. More subtly, but perhaps more profoundly, we introduced three socio-technical principles as the basis of this theorizing. These principles engage us to consider people's actions as coequals with tasks, to focus on processes as flexible and contextual, and to highlight both the structural and agent-like nature of people and tools. If one takes seriously our position-that software development methods are incipient theories-then the socio-technical principles of theorizing provide the conceptual guidance for how to proceed.

\section{References}

Andersson, R., and Nilsson, A. "The Standard Application Package Market-An Industry in Transition?," in M. Lundeberg and B. Sundgren (eds.), Advancing Your Business: People and Information Systems in Concert, Stockholm: EFI, Stockholm School of Economics, 1996. 
Annabi, H. Moving from Individual Contribution to Group Learning: The Early Years of the Apache Web Server, unpublished Ph.D. dissertation, Syracuse University, Syracuse, New York, 2005.

Bergquist, M., and Ljungberg, J. "The Power of Gifts: Organizing Social Rrelationships in Open Source Communities," Information Systems Journal (11:4), 2001, pp. 305-320.

Bezroukov, N. "A Second Look at the Cathedral and the Bazaar," First Monday (4:12), 1999.

Bijker, W. Of Bicycles, Bakelites, and Bulbs: Toward a Theory of Socio-Technical Change, Cambridge, MA: MIT Press, 1995.

Bijker, W., Hughes, T. , and Pinch, T. The Social Construction of Technological Systems, Cambridge, MA: MIT Press, 1987.

Brynjolfsson, E. "The Productivity Paradox of Information Technology," Communications of the $A C M(36: 12), 1994$, pp. 67-77.

Carmel, E. "American Hegemony in Packaged Software Trade and the "Culture of Software,"” The Information Society (13:1), 1997, pp. 125-142.

Carmel, E. "Cycle-Time in Packaged Software Firms," Journal of Product Innovation Management (12:2), 1995, pp. 110-123.

Carmel, E., and Becker, S. "A Process Model for Packaged Software Development," IEEE Transactions on Engineering Management (41:5), 1995, pp. 50-61

Carmel, E., and Sawyer, S. "Packaged Software Development Teams: What Makes Them Different?," Information Technology \& People (11:1), 1998, pp. 7-19.

Crowston, K., Annabi, H., and Howison, J. "Defining Open Source Software Project Success," in S. T. March, A. Massey, and J. I. DeGross (eds.), Proceedings of the $24^{\text {th }}$ International Conference for Information Systems, Seattle, WA, December 2003, pp. 327-340.

Cubranic, D., and Booth, K. S. "Coordinating Open-Source Software Development," paper presented at the Seventh IEEE Workshop on Enabling Technologies: Infrastructure for Collaborative Enterprises, 1999.

Cusumano, M., and Smith, S. "Beyond the Waterfall: Software Development at Microsoft," in D. Yoffie (ed.), Competing in the Age of Digital Convergence, Boston: Harvard Business School Press, 1997, pp. 371-411.

Drucker, P. F. "Management's New Paradigms," Forbes (162), 1998, pp. 152-177.

Egyedi, T. M. "Standardization and Other Coordination Mechanisms in Open Source oSftware," International Journal of IT Standards \& Standardization Research (2:2), 2004, pp. 1-17.

Fielding, R. T. "The Apache Group: A Case Study of Internet Collaboration and Virtual Communities," UCI School of Social Sciences Seminar Series, University of California, Irvine, 1997 (available online at http://roy.gbiv.com/talks/ssapache/title.htm).

Goodman, P., Ravlin, E., and Argote, L. "Current Thinking About Groups: Setting the Stage for New Ideas," in P. Goodman and Associates (eds.), Designing Effective Work Groups, San Francisco: Jossey-Bass, 1986, pp. 1-33.

Grudin, J. "Interactive Systems: Bridging the Gap between Developers and Users," IEEE Computer (24:5), 1991, pp. 59-69.

Halloran, T. , and Scherlis, W. "High Quality and Open Source Software Practices," paper presented at the Second Workshop on Open Source Software Engineering, Orlando, FL, May 2002.

Hecker, F. "Mozilla at One: A Look Back and Ahead," Mozilla.org, April 2, 1999 (available online at http://www.mozilla.org/mozilla-at-one.html).

Keil, M., and Carmel, E. "Customer-Developer Links in Software Development," Communications of the ACM (38:5), 1995, pp. 33-44.

Kling, R. "Learning about Information Technologies and Social Change: The Contribution of Social Informatics," The Information Society (16:3), 2000, pp. 212-234. 
Kling, R. "What Is Social Informatics and Why Does it Matter?," D-Lib Magazine (5:1), January 1999 (available online at http://www.dlib.org:80/dlib/january99/kling/0lkling.html).

Kling, R., and Iacono, S. "The Control of Information Systems Developments After Implementation," Communications of the ACM (27:12), 1984, pp. 1218-1226.

Kling, R., Rosenbaum, H., and Sawyer, S. Understanding and Communicating Social Informatics: A Framework for Studying and Teaching the Human Contexts of Information and Communication Technologies, Medford, NJ: Information Today, 2005.

Law, J., and Bijker, W. "Technology, Stability and Social Theory," in W. Bijker (ed.), Shaping Technology/Building Society, Cambridge, MA: MIT Press, 1992, pp. 32-50.

Maiden, N., and Ncube, C. "Acquiring COTS Software Selection Requirements," IEEE Software (15:2), 1998, pp. 46-56.

Markus, M. "Power, Politics, and MIS Implementation," Communications of the ACM (26:6), 1983, pp. 430-444.

Melone, N. "A Theoretical Assessment of the User-Satisfaction Construct in Information Systems Research," Management Science (36:1), 1990, pp. 76-91.

Merton, R. On Theoretical Sociology, New York: The Free Press, 1967.

Mockus, A., and Herbsleb, J. "Why Not Improve Coordination in Distributed Software Development by Stealing Good Ideas from Open Source?," paper presented at the Second Workshop on Open Source Software Engineering, Orlando, FL, May 2002.

Moody, G. Rebel Code-Inside Linux and the Open Source Movement, Cambridge, MA: Perseus Publishing, 2001.

Moon, J. Y., and Sproull, L. "Essence of Distributed Work: The Case of Linux Kernel," First Monday (5:11), 2000 (available online at http://www.firstmonday.org/ issues/issue 5 _11/moon/index.html).

Raymond, E. S. "The Cathedral and the Bazaar," First Monday (3:3), 1998 (available online at http://www.firstmonday.org/issues/issue3_3/raymond/index.html).

Sawyer, S. "Information Systems Development: A Market-Oriented Perspective," Communications of the ACM (44:11), 2001, pp. 97-102.

Sawyer, S. "Packaged Software: Implications of the Differences from Custom Approaches to Software Development," European Journal of Information Systems (9:1), 2001, pp. 47-58.

Sawyer, S. "Social Informatics: Principles and Opportunties," Bulletin of the American Society for Information Science and Technology, June 2005, pp. 2-6.

Sawyer, S. "Software Development Teams: Three Archetypes and Their Differences." Communications of the ACM (17:12), 2004, pp. 92-97.

Scacchi, W. "Process Models in Software Engineering," in J. Marciniak (ed.), Encyclopedia of Software Engineering ( $2^{\text {nd }}$ ed.), New York: Wiley, 2002a, pp. 993-1005.

Scacchi, W. "Socio-Technical Interaction Networks in Free/Open Source Software Development Processes," in S. T. Acuña and N. Juristo (eds.), Software Process Modeling, New York: Springer Science+Business Media Inc., 2005, pp. 1-27.

Scacchi, W. "Understanding the Requirements for Developing Open Source Ssoftware Systems.," IEE Proceedings-Software (14:1), 2002b, pp. 24-39.

Shaikh, M., and Cornford, T. "Version Control Tools: A Collaborative Vehicle for Learning in F/OS," paper presented at the $26^{\text {th }}$ International Conference on Software Engineering: Collaboration, Conflict and Control: The Fourth Workshop on Open Source Software Engineering, Edinburgh, Scotland., May 25, 2004.

Vessey, I., and Sravanapudi, P. "Case Tools as Collaborative Support Technologies," Communications of the ACM (38:1), 1995, pp. 83-95.

Weick, K. "What Theory Is Not: Theorizing Is," Administrative Science Quarterly (40), 1995, pp. 385-390. 


\section{About the Authors}

Steve Sawyer conducts research on social and organizational informatics, studying how people work together and how they use information and communication technologies. His most recent research programs include investigating how software development can be improved through attending to the social aspects of working together; studying how people adapt to working with large-scale information systems implementations (such as enterprise resource packages); and understanding the changes to organizations (and organizational work) due to the increased distribution of computing. Corning, IBM, Sonoco, Xerox, the Lattanze Foundation, and the National Science Foundation have supported his research. Steve teaches information systems analysis and design, project management, and implementation; information-technology-enabled organizational change; social informatics; and field-based research methods. He can be reached at sawyer@ist.psu.edu.

Hala Annabi is an assistant professor at the Information School at the University of Washington. Her research addresses the effects of information technology on learning in both the work and educational settings. More specifically, she studies how the new forms of computer mediated work affect individual, group and organizational learning in distributed work settings. She is currently investigating group learning in Open Source Software development teams and organizational learning in distributed multinational engineering firm. Additionally, she is interested in the effects of asynchronous learning networks on learning in educational settings. She is currently investigating how asynchronous learning networks can be used to improve learning and student satisfaction in large lecture style courses. Her teaching interests are in the impact of information technology on organizations, organizational learning and knowledge management, and organizational behavior. For more information please contact Hala at hpannabi@u.washington.edu. 